\title{
Maximum Loadability Estimation for Weak Bus Identification using Line Stability Indices
}

\author{
Ankit Kumar Sharma ${ }^{1}$, Akash Saxena ${ }^{1}$ and Rajive Tiwari ${ }^{2}$ \\ ${ }^{1}$ Research Scholar, ${ }^{1}$ Reader,${ }^{2}$ Associate Professor \\ ${ }^{1}$ Department of Electrical Engineering, SKIT, Jaipur, India \\ ${ }^{2}$ Department of Electrical Engineering, Malaviya National Institute of \\ Technology, Jaipur, India \\ 1*ankit.krishnaa@gmail.com, ${ }^{2}$ akash@skit.ac.in, ${ }^{2}$ rajive.tiwari@yahoo.co.in
}

\begin{abstract}
At present, the voltage stability assessment experiences sizeable agitation in the safe operation of power systems. This is due to the blow of a strain power system. With the accretion of power demand by the consumers and also the ambit amount of power sources, therefore, the system has to perform at its maximum accuracy. Consequently, the cardinally to discover the maximum ability boundary prior to voltage collapse should be undertaken. A preliminary warning can be perceived to avoid accost capacity of power system. This has necessitated the employment of techniques for determination of critical point of voltage stability. In this paper some important aspects related to voltage stability indices use in electric power system are discussed. The line indices are used for estimation of the maximum loadability and in other words indices are used to identify the weak bus in the system. The effectiveness of the analyzed methods are demonstrated through numerical studies in IEEE 14 test bus system, IEEE 30 test bus system and IEEE 118 test bus system, using Fast Voltage Stability Index (FVSI) and Line stability index $\left(L_{m n}\right)$ at base loading and heavy reactive loading. This will be very useful in placement of optimal FACTS devices for enhancement the margin of voltage stability.
\end{abstract}

Keywords: FVSI, $L_{m n}$, IEEE test bus system

\section{Introduction}

Voltage stability is a major concern for designing a foolproof power network. In recent years deregulation of the power system has ignited competitive business environment between Generating Companies (Gencos) and Distribution Companies. Hence, reliability of power system has become a major concern in this environment. With this fact assessment of voltage stability along with the preventive control actions are major area of research. Transmission network expansion can be a solution for this but it requires time to expand this utility. There is an acute need of a technique for assessment of the critical point of the voltage stability. Stressed transmission network is prone to voltage collapse. Therefore, voltage stability analysis is necessary to identify the critical buses in a power system so that the planning engineers and operators may take appropriate actions to avoid the voltage collapse. The use of line index termed as Fast Voltage Stability Index (FVSI) and Line Stability Index $\left(\mathrm{L}_{\mathrm{mn}}\right)$ in order to examine the maximum loadability in power system. Voltage stability analysis is conducted using line index indicated by FVSI and $\mathrm{L}_{\mathrm{mn}}$ to indicate the stressfulness of a line in a transmission system. The reactive power at a particular bus is increased until it reaches the instability point at bifurcation. At this instability point, the load connected at the particular bus is determined as the maximum loadability. The maximum loadability for every load bus will be sorted in ascending order with smallest value being ranked top. The highest or top rank implies the weak bus in the 
system that has the lowest sustainable load in the system. This technique is tested on the IEEE-14 bus system, IEEE-30 bus system and IEEE-118 bus system. The Weak area of the practical system and the ranking with overloading are found or examined by using FVSI and $\mathrm{L}_{\mathrm{mn}}$. When brief on the related search then we get, K.R.Vadivelu et al. discussed voltage stability analysis using line stability index advocated by Fast Voltage Stability Index (FVSI) [1]. C M Arora et al. used repeated power flow technique to the study the consequences of loadability on voltage stability [2]. Claudia Reis et al. presented a comparative analysis of the performance of static voltage collapse indices. The voltage stability margin developed by using P-V and Q-V curves, L-index (proposed by Kessel et al), V/Vo index, Model Analysis (proposed by Gao et al), Line stability index $\mathrm{L}_{\mathrm{mn}}$ (proposed by M.Moghavemmi et al), Line stability index FVSI (proposed by I.K.Musirin et $a l$ ), Line stability index LQP (proposed by A.Mohamed et al), Line stability index VCPI (proposed by M.Moghavemmi) [3]. Krishna Nandlal et al. developed voltage stability assessment MATLAB toolbox yielding marginal and analytical assessment of voltage stability [4]. Z.J.Lim et al. and M.V.Suganyadevi et al. discussed the various VSI such as L $_{\mathrm{mn}}$, FVSI, LQP, LP and NLSI on IEEE-14 bus system [5] [6]. Ismail Musirin et al. discussed a new line voltage stability namely Fast Voltage Stability Index (FVSI). The values of FVSI indicated the voltage stability condition in the power system and it used to rank the line contingency [7]. Ismail Musirin et al. discussed about the FVSI simplified from a pre-developed VSI referred to a line initiated from the voltage quadratic equation at sending end of 2-bus system. The results of proposed index are verified by using line index $\mathrm{L}_{\mathrm{mn}}$ and LQP [8]. Rajive Tiwari et al. discussed about a new index named Line Collapse Proximity Index (LCPI) for assessment of voltage stability. This index based on exact model of transmission system. This proposed index also compared with FVSI, $\mathrm{L}_{\mathrm{mn}}$ and LQP indices at different loading conditions. The main feature of proposed index is that it incorporates the effect of relative directions of active and reactive power flows in the line to predict the collapse. The effectiveness of proposed index is examined by using the contingency analysis at base load. The proposed technique tested on IEEE-30 and IEEE-118 bus system [9]. Idea about the different methods of voltage stability assessment using line indices and also using Artificial neural networks is taken from [11] [12], apart it, control strategies and cost of FACTS devices discussed in [13].

In the view of literature survey, following research objectives are formed for this paper.

a. To present the mathematical frame work of FVSI and $\mathrm{L}_{\mathrm{mn}}$, calculate the same for three standard IEEE networks (14, 30 and 118 bus test systems).

b. To identify the weak buses in networks by the application of line voltage stability indices namely, FVSI and $\mathrm{L}_{\mathrm{m} n}$.

c. Analyze the loadability of systems at base case and high reactive loading.

d. To present the comparison of the system loadability using FVSI and $\mathrm{L}_{\mathrm{mn}}$.

Rest part of the paper is organized as follows in section 2 mathematical frame work of FVSI and $L_{m n}$ are presented. In section 3 simulation results are presented last but not the least in section 4 conclusion of the work is presented. 


\section{Index Formulation}

\subsection{Fast Voltage Stability Index (FVSI) Formulation}

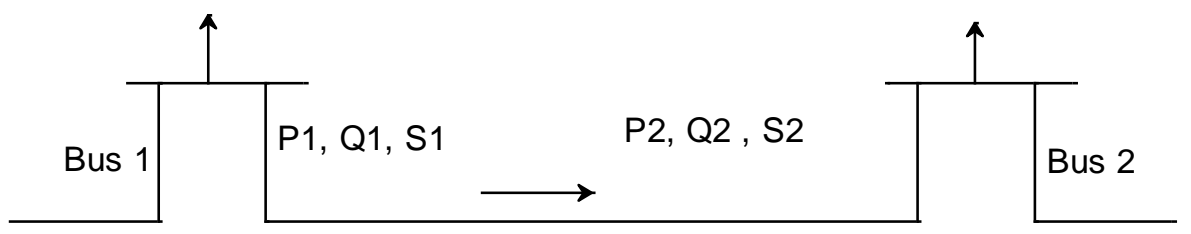

$R+j X$

Figure 1. Two Bus Equivalent Systems

The FVSI is derived from the voltage quadratic equation at the receiving bus on a twobus system.

From the figure, the voltage quadratic equation at the receiving bus is written as:

$$
V^{2}{ }_{2}-\left[\frac{R}{X} \sin \delta+\cos \delta\right] V_{1} V_{2}+\left(X+\frac{R^{2}}{X}\right) Q_{2}=0
$$

Rewrite the equation:

$$
\left(\left[\frac{R}{X} \sin \delta+\cos \delta\right] V_{1}\right)^{2}+4\left(X+\frac{R^{2}}{X}\right) Q_{2} \geq 0
$$

Rearranging (2), we obtain:

$$
\frac{4 Z^{2} Q_{2} X}{V_{1}{ }^{2}(R \sin \delta+X \cos \delta)^{2}}<1
$$

Since "s" as the sending bus and " $\mathrm{r}$ " as the receiving end bus, since $\delta$ is normally very small \& negligible, then, $\delta \approx 0$, Rsin $\delta \approx 0$ and $X \cos \delta \approx X$. Taking the symbols " $s$ " as the sending bus and " $r$ " as the receiving bus, FVSI can be calculated [8].

$$
F V S I_{S r}=\frac{4 z^{2} Q_{r}}{V_{s}^{2} X}
$$

\subsection{Line Stability Index $\left(\mathbf{L}_{\mathrm{mn}}\right)$ Formulation}

The Line Stability Index proposed by Mohavani and Omar (1998). It is symbolized by $\mathrm{L}_{\mathrm{mn}}$. The Line Stability Index is given by

$$
L_{m n}=\frac{4 Q_{r} X}{\left[\left|V_{s}\right| \sin (\theta-\delta)\right]^{2}}
$$

Where

$\mathrm{X}=$ Line Reactance

$Q_{r}=$ Reactive power at the receiving end

$V_{S}=$ Sending end voltage

$\theta=$ Line impedance angle

$\delta=$ Angle difference between supply voltage and receiving end voltage 


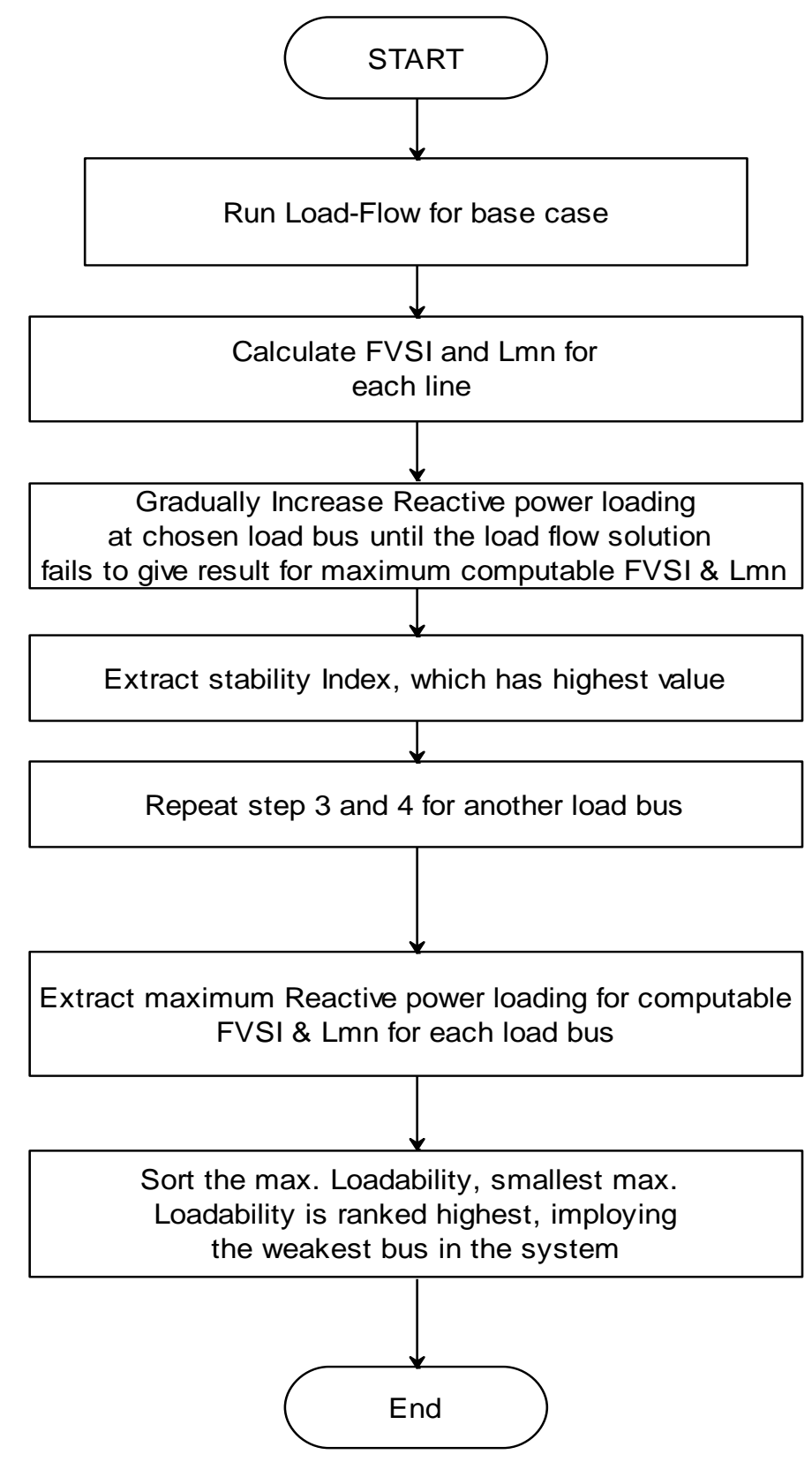

Figure 2. Proposed Algorithm for Determining the Maximum Load Ability for Weak Bus Identification

\section{Results and Discussion}

A computer software programme has been designed to know the sequence of weak buses in given system in the MATLAB $2015^{\mathrm{b}}$ environment to perform the simulations.

To demonstrate the effectiveness of the proposed technique, an IEEE 14 bus test system, IEEE 30 bus test system and a typical IEEE 118 bus test system have been used. The result for bus ranking based on maximum loadability using FVSI and $\mathrm{L}_{\mathrm{mn}}$ are tabulated. The bus ranking could be performed by sorting the maximum loadability in ascending order. 


\subsection{Case Study on IEEE-14 Bus System}

The IEEE 14 Bus system represents a portion of the American Electric Power System which is located in the Midwestern US as of February, 1962. Basically this 14 bus system has 14 buses, 5 generators and 9 load buses. To validate the proposed approach two operating scenarios are considered [10].

Case1. Base case (where the load buses are having the nominal values of real and reactive power)

Case2. High Reactive Loading (increase of the system's reactive load by (3.2 p.u. from base case)

Tables 1 and 2 give the Line stability index FVSI and $\mathrm{L}_{\mathrm{mn}}$ for IEEE 14 test bus system at for two cases, respectively. Following results are emerged from this analysis.

$>$ Most five weakest buses in IEEE-14 bus system are bus no. 14, 12, 11, 10 and 13 according to their loadability.

$>$ At the base case no buses are weak.

Table 1. Line Stability Indices for IEEE 14 Test Bus Systems with Base Load Condition

\begin{tabular}{cccc}
\hline From & To & FVSI & L $_{\text {mn }}$ \\
\hline 5 & 1 & $\mathbf{0 . 0 0 6}$ & $\mathbf{0 . 0 0 6}$ \\
9 & 4 & $\mathbf{0 . 0 3 8}$ & $\mathbf{0 . 0 3 9}$ \\
13 & 6 & $\mathbf{0 . 0 5 5}$ & $\mathbf{0 . 0 5 4}$ \\
10 & 11 & $\mathbf{0 . 0 5 2}$ & $\mathbf{0 . 0 5 1}$ \\
11 & 6 & $\mathbf{0 . 0 7 1}$ & $\mathbf{0 . 0 7}$ \\
12 & 6 & $\mathbf{0 . 0 3 3}$ & $\mathbf{0 . 0 3 3}$ \\
14 & 13 & $\mathbf{0 . 0 7 4}$ & $\mathbf{0 . 0 7 3}$ \\
\hline
\end{tabular}

Table 2. Line Stability Indices for IEEE 14 Test Bus Systems With Heavy Reactive Loading

\begin{tabular}{ccccc}
\hline Ranking & Bus (Load) & Qm & FVSI & L $_{\text {mn }}$ \\
\hline 1 & 14 & 0.75 & 0.999 & 0.987 \\
2 & 12 & 0.912 & $\mathbf{0 . 9 8 9}$ & $\mathbf{0 . 9 8 6}$ \\
3 & 11 & 1.008 & $\mathbf{0 . 9 9 6}$ & $\mathbf{0 . 9 7 6}$ \\
4 & 10 & 1.392 & $\mathbf{0 . 9 3 3}$ & $\mathbf{0 . 9 7 3}$ \\
5 & 13 & 1.4732 & $\mathbf{0 . 9 9 7}$ & $\mathbf{0 . 9 7 6}$ \\
6 & $\mathbf{9}$ & $\mathbf{1 . 5 7 7}$ & $\mathbf{0 . 9 6 6}$ & $\mathbf{0 . 9 7 3}$ \\
7 & $\mathbf{5}$ & $\mathbf{3 . 0 0 8}$ & $\mathbf{0 . 9 9 9}$ & $\mathbf{0 . 9 5 5}$ \\
\hline
\end{tabular}




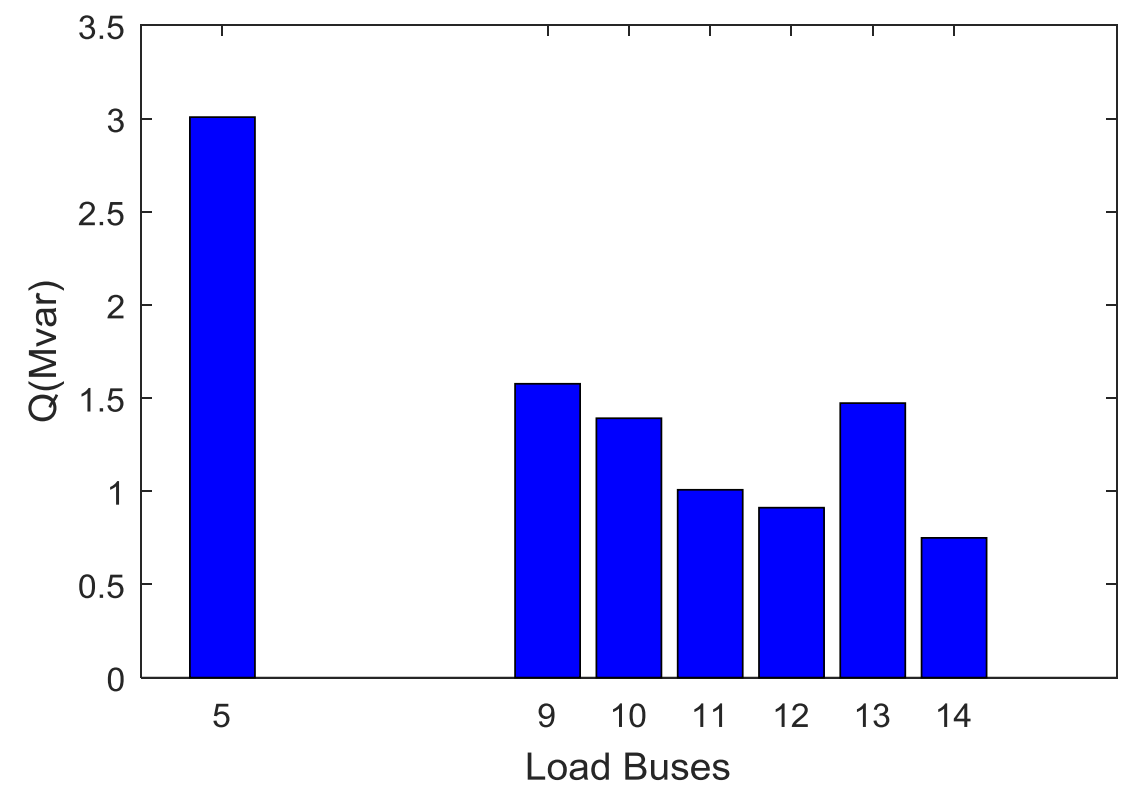

\section{Figure 3. Maximum Permissible Reactive Loading (p.u.) of Load Buses in IEEE 14-Bus Test System}

After following the algorithm of maximum loadability, we get the maximum permissible reactive loading (p.u.) of load buses in IEEE-14 system, which is given in Figure 3. On the basis these charts the voltage weak nodes and area can be identified. Following point is emerged from this analysis.

In IEEE 14 bus system, nodes 14, 12 and 11 are found to be voltage weak nodes of the system as these nodes have smaller permissible reactive loading. Therefore area containing these buses is considered as the weakest area of the system. The bus 5 is most robust load bus of the area since it has highest permissible reactive loading of value 3.008 p.u., as can see in Figure 3.

\subsection{Case Study on IEEE-30 Bus System}

The IEEE 30 Bus system represents a portion of the American Electric Power System (in the Midwestern US) as of December, 1961. Basically this 30 bus system has 30 buses, 6 generators and 24 load buses. To validate the proposed approach two operating scenarios are considered [10].

Case1. Base case (where the load buses are having the nominal values of real and reactive power)

Case2. High Reactive Loading (increase of the system's reactive load by (2.7 p.u. from base case)

Tables 3 and 4 give the Line stability index FVSI and $\mathrm{L}_{\mathrm{mn}}$ for IEEE 30 test bus system at for two cases, respectively. Following results are emerged from this analysis.

Most five weakest buses in IEEE-30 bus system are bus no. 26, 30, 29, 20 and 18 according to their loadability.

$>\quad$ At the base case no buses are weak. 
Table 3. Line Stability Indices for IEEE $\mathbf{3 0}$ Test Bus Systems with Base Load Condition

\begin{tabular}{|cccc}
\hline From & To & FVSI & L $_{\text {mn }}$ \\
\hline 6 & 28 & $\mathbf{0 . 0 2 4}$ & $\mathbf{0 . 0 2 4}$ \\
\hline 7 & $\mathbf{5}$ & $\mathbf{0 . 0 6 5}$ & $\mathbf{0 . 0 6 6}$ \\
\hline 10 & 9 & $\mathbf{0 . 0 2 4}$ & $\mathbf{0 . 0 2 4}$ \\
\hline 12 & $\mathbf{1 3}$ & $\mathbf{0 . 0 5 2}$ & $\mathbf{0 . 0 5 2}$ \\
\hline 12 & $\mathbf{1 6}$ & $\mathbf{0 . 0 2 9}$ & $\mathbf{0 . 0 3}$ \\
\hline 16 & 17 & $\mathbf{0 . 0 1 2}$ & $\mathbf{0 . 0 1 2}$ \\
\hline 20 & 10 & $\mathbf{0 . 0 3 2}$ & $\mathbf{0 . 0 3 2}$ \\
\hline 20 & 19 & $\mathbf{0 . 0 0 9}$ & $\mathbf{0 . 0 0 9}$ \\
\hline 25 & 24 & $\mathbf{0 . 0 2 7}$ & $\mathbf{0 . 0 2 7}$ \\
\hline 28 & 27 & $\mathbf{0 . 0 8 5}$ & $\mathbf{0 . 0 8 5}$ \\
\hline 29 & 27 & $\mathbf{0 . 0 3 2}$ & $\mathbf{0 . 0 3 1}$ \\
\hline 30 & 27 & $\mathbf{0 . 0 4 2}$ & $\mathbf{0 . 0 4 1}$ \\
\hline 30 & 29 & $\mathbf{0 . 0 1 3}$ & $\mathbf{0 . 0 1 3}$ \\
\hline
\end{tabular}

Table 4. Line Stability Indices for IEEE 30 Test Bus Systems with Heavy Reactive Loading

\begin{tabular}{ccccc}
\hline Ranking & Bus & Qm & FVSI & $\mathbf{L}_{\mathbf{m n}}$ \\
\hline $\mathbf{1}$ & 26 & 0.2622 & 0.985 & 0.999 \\
$\mathbf{2}$ & 30 & 0.2831 & 0.971 & 0.992 \\
$\mathbf{3}$ & 29 & 0.324 & 0.999 & 0.997 \\
$\mathbf{4}$ & 20 & 0.8043 & 0.998 & 0.999 \\
$\mathbf{5}$ & 18 & 0.8145 & 0.994 & 0.998 \\
$\mathbf{6}$ & 23 & 0.832 & 0.993 & 0.995 \\
$\mathbf{7}$ & 14 & 0.832 & 0.999 & 0.996 \\
$\mathbf{8}$ & 24 & 0.9916 & 0.997 & 0.984 \\
$\mathbf{9}$ & 19 & 0.9962 & 0.91 & 0.991 \\
$\mathbf{1 0}$ & 16 & 1.035 & 0.991 & 0.997 \\
$\mathbf{1 1}$ & 15 & 1.385 & 0.998 & 0.999 \\
$\mathbf{1 2}$ & 17 & 1.4969 & 0.989 & 0.999 \\
$\mathbf{1 3}$ & 21 & 1.6576 & 0.977 & 0.97 \\
$\mathbf{1 4}$ & 10 & 1.68 & 0.999 & 0.999 \\
$\mathbf{1 5}$ & 3 & 2.4156 & 0.999 & 0.999 \\
$\mathbf{1 6}$ & 12 & 2.1375 & 0.999 & 0.994 \\
$\mathbf{1 7}$ & 7 & 2.4416 & 0.988 & 0.999 \\
$\mathbf{1 8}$ & 4 & 4.08 & 0.999 & 0.999 \\
\hline
\end{tabular}




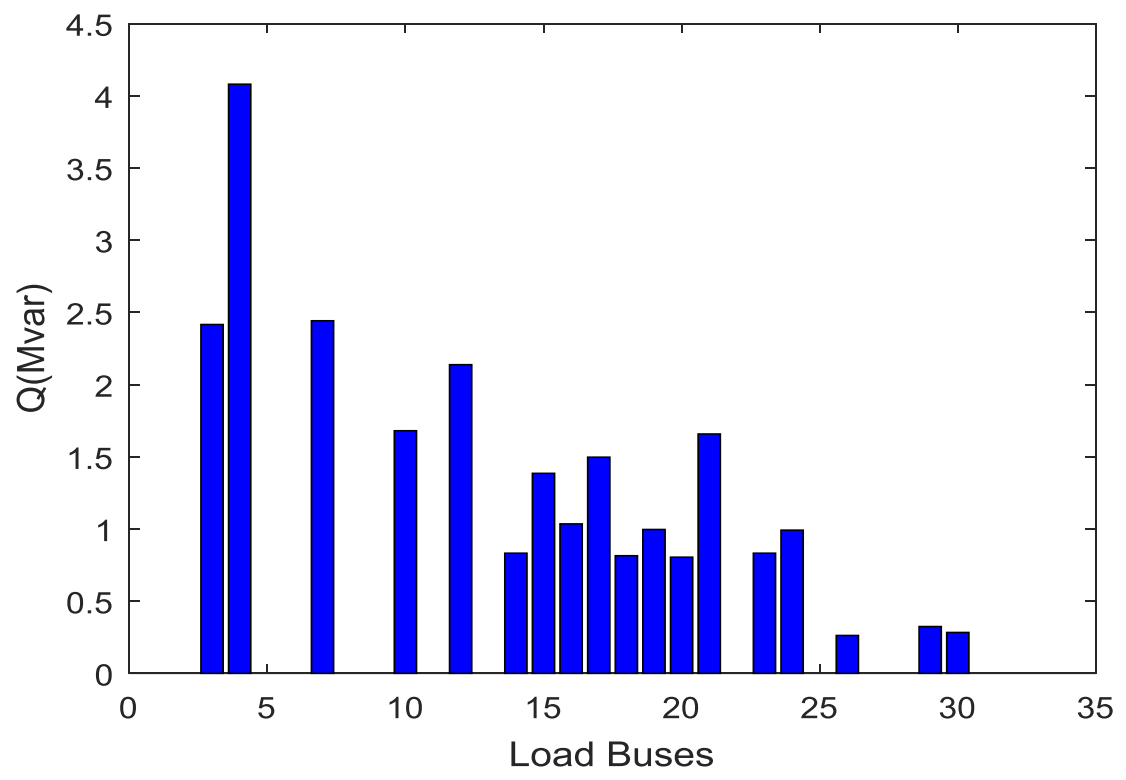

Figure 4. Maximum Permissible Reactive Loading (p.u.) of Load Buses in IEEE 30-Bus Test System

After following the algorithm of maximum loadability, we get the maximum permissible reactive loading (p.u.) of load buses in IEEE-30 system, which is given in Figure 4. On the basis these charts the voltage weak nodes and area can be identified. Following point is emerged from this analysis.

In IEEE 30 bus system, nodes 18,20, 25, 26, 27, 29 and 30 are found to be voltage weak nodes of the system as these nodes have smaller permissible reactive loading. Therefore area containing these buses is considered as the weakest area of the system. Area comprising load buses 3, 4, 6, 7 and 9 is observed to be the strong area have larger permissible reactive loading. It is expected results since most of the generator buses are located in the surrounding area. The bus 4 is most robust load bus of the area since it has highest permissible reactive loading of value 4.08 p.u., as can see in Figure 4.

\subsection{Case Study on IEEE-118 Bus System}

The IEEE 118 has the 118 buses, 51 generators and 67 load buses [10].

Case1. Base case (where the load buses are having the nominal values of real and reactive power)

Case2. High Reactive Loading (increase of the system's reactive load by (1.77 p.u. from base case)

Tables 5 and 6 give the Line stability index FVSI and $\mathrm{L}_{\mathrm{mn}}$ for IEEE 118 test bus system at for two cases, respectively. Following results are emerged from this analysis.

$>$ Most five weakest buses in IEEE-118 bus system are bus no. 117, 43, 22, 20 and 86 according to their loadability.

$>$ At the base case no buses are weak. 
Table 5. Line Stability Indices for IEEE 118 Test Bus System with Base Load Condition

\begin{tabular}{cccc}
\hline From & To & FVSI & $\mathbf{L}_{\mathbf{m n}}$ \\
\hline $\mathbf{3}$ & 12 & 0.101 & 0.1 \\
$\mathbf{5}$ & 8 & 0.124 & 0.125 \\
$\mathbf{1 3}$ & 11 & 0.036 & 0.036 \\
$\mathbf{2 5}$ & 26 & 0.026 & 0.026 \\
$\mathbf{3 0}$ & 8 & 0.142 & 0.141 \\
$\mathbf{3 7}$ & 38 & 0.136 & 0.137 \\
$\mathbf{3 8}$ & 65 & 0.282 & 0.279 \\
$\mathbf{5 1}$ & 49 & 0.113 & 0.107 \\
$\mathbf{5 4}$ & 49 & 0.198 & 0.189 \\
$\mathbf{5 5}$ & 59 & 0.084 & 0.082 \\
$\mathbf{6 2}$ & 66 & 0.158 & 0.154 \\
$\mathbf{6 6}$ & 65 & 0.095 & 0.095 \\
$\mathbf{6 7}$ & 66 & 0.078 & 0.077 \\
$\mathbf{6 9}$ & 68 & 0.136 & 0.136 \\
$\mathbf{7 5}$ & 69 & 0.185 & 0.178 \\
$\mathbf{7 7}$ & 69 & 0.198 & 0.205 \\
$\mathbf{8 0}$ & 81 & 0.098 & 0.098 \\
$\mathbf{8 6}$ & 87 & 0.131 & 0.131 \\
$\mathbf{9 6}$ & 80 & 0.25 & 0.252 \\
$\mathbf{9 9}$ & 80 & 0.195 & 0.202 \\
$\mathbf{9 4}$ & 100 & 0.12 & 0.119 \\
$\mathbf{9 7}$ & 80 & 0.134 & 0.134 \\
$\mathbf{9 8}$ & 80 & 0.086 & 0.087 \\
$\mathbf{1 0 6}$ & 105 & 0.023 & 0.023 \\
$\mathbf{1 1 4}$ & 32 & 0.028 & 0.028 \\
$\mathbf{1 1 5}$ & 27 & 0.002 & 0.002 \\
$\mathbf{1 1 8}$ & 75 & 0.08 & 0.08 \\
\hline & & & \\
\hline
\end{tabular}

Table 6. Line Stability Indices for IEEE 118 Test Bus Systems with Heavy Reactive Loading

\begin{tabular}{ccccc}
\hline Ranking & Bus (Load) & Qm & FVSI & $\mathbf{L}_{\mathbf{m n}}$ \\
\hline $\mathbf{1}$ & 117 & 1 & 0.991 & 0.994 \\
$\mathbf{2}$ & 43 & 1.19 & 0.908 & 0.915 \\
$\mathbf{3}$ & 22 & 1.25 & 0.903 & 0.913 \\
$\mathbf{4}$ & 20 & 1.5 & 0.972 & 0.986 \\
$\mathbf{5}$ & 86 & 1.5 & 0.934 & 0.94 \\
$\mathbf{6}$ & 53 & 1.54 & 0.901 & 0.909 \\
$\mathbf{7}$ & 44 & 1.68 & 0.939 & 0.97 \\
$\mathbf{8}$ & 21 & 1.68 & 0.878 & 0.907 \\
$\mathbf{9}$ & 101 & 1.8 & 0.941 & 0.974 \\
$\mathbf{1 0}$ & 33 & 1.89 & 0.958 & 0.974 \\
$\mathbf{1 1}$ & 51 & 2 & 0.97 & 0.916 \\
$\mathbf{1 2}$ & 52 & 2 & 0.965 & 0.945 \\
$\mathbf{1 3}$ & 45 & 2.09 & 0.903 & 0.876 \\
$\mathbf{1 4}$ & 57 & 2.1 & 0.933 & 0.998 \\
$\mathbf{1 5}$ & 58 & 2.1 & 0.933 & 0.933 \\
$\mathbf{1 6}$ & 98 & 2.16 & 0.961 & 0.991 \\
\hline
\end{tabular}




\begin{tabular}{|c|c|c|c|c|}
\hline 17 & 16 & 2.3 & 0.998 & 0.984 \\
\hline 18 & 13 & 2.368 & 0.984 & 0.981 \\
\hline 19 & 50 & 2.4 & 0.957 & 0.966 \\
\hline 20 & 97 & 2.52 & 0.935 & 0.97 \\
\hline 21 & 67 & 2.52 & 0.95 & 0.95 \\
\hline 22 & 14 & 2.58 & 0.995 & 0.945 \\
\hline 23 & 84 & 2.59 & 0.947 & 0.986 \\
\hline 24 & 109 & 2.79 & 0.984 & 0.998 \\
\hline 25 & 28 & 2.8 & 0.977 & 0.988 \\
\hline 26 & 102 & 3 & 0.913 & 0.916 \\
\hline 27 & 93 & 3.15 & 0.995 & 0.983 \\
\hline 28 & 106 & 3.2 & 0.987 & 0.953 \\
\hline 29 & 2 & 3.24 & 0.983 & 0.992 \\
\hline 30 & 88 & 3.3 & 0.997 & 0.978 \\
\hline 31 & 115 & 3.36 & 0.955 & 0.985 \\
\hline 32 & 48 & 3.465 & 0.984 & 0.965 \\
\hline 33 & 41 & 3.5 & 0.921 & 0.931 \\
\hline 34 & 39 & 3.52 & 0.957 & 0.982 \\
\hline 35 & 82 & 3.699 & 0.977 & 0.996 \\
\hline 36 & 83 & 3.7 & 0.973 & 0.928 \\
\hline 37 & 96 & 3.75 & 0.992 & 0.945 \\
\hline 38 & 114 & 3.9 & 0.937 & 0.95 \\
\hline 39 & 95 & 4.03 & 0.938 & 0.988 \\
\hline 40 & 118 & 4.35 & 0.988 & 0.988 \\
\hline 41 & 3 & 4.55 & 0.995 & 0.964 \\
\hline 42 & 29 & 4.6 & 0.98 & 0.996 \\
\hline 43 & 75 & 4.84 & 0.989 & 0.968 \\
\hline 44 & 94 & 5.12 & 0.98 & 0.995 \\
\hline 45 & 79 & 5.44 & 0.935 & 0.926 \\
\hline 46 & 23 & 5.85 & 0.936 & 0.908 \\
\hline 47 & 7 & 10.6 & 0.997 & 0.999 \\
\hline 48 & 11 & 11.04 & 0.991 & 0.989 \\
\hline 49 & 60 & 12 & 0.971 & 0.999 \\
\hline 50 & 78 & 12.61 & 0.974 & 0.988 \\
\hline 51 & 17 & 13.2 & 0.994 & 0.999 \\
\hline 52 & 35 & 16.2 & 0.982 & 0.982 \\
\hline
\end{tabular}




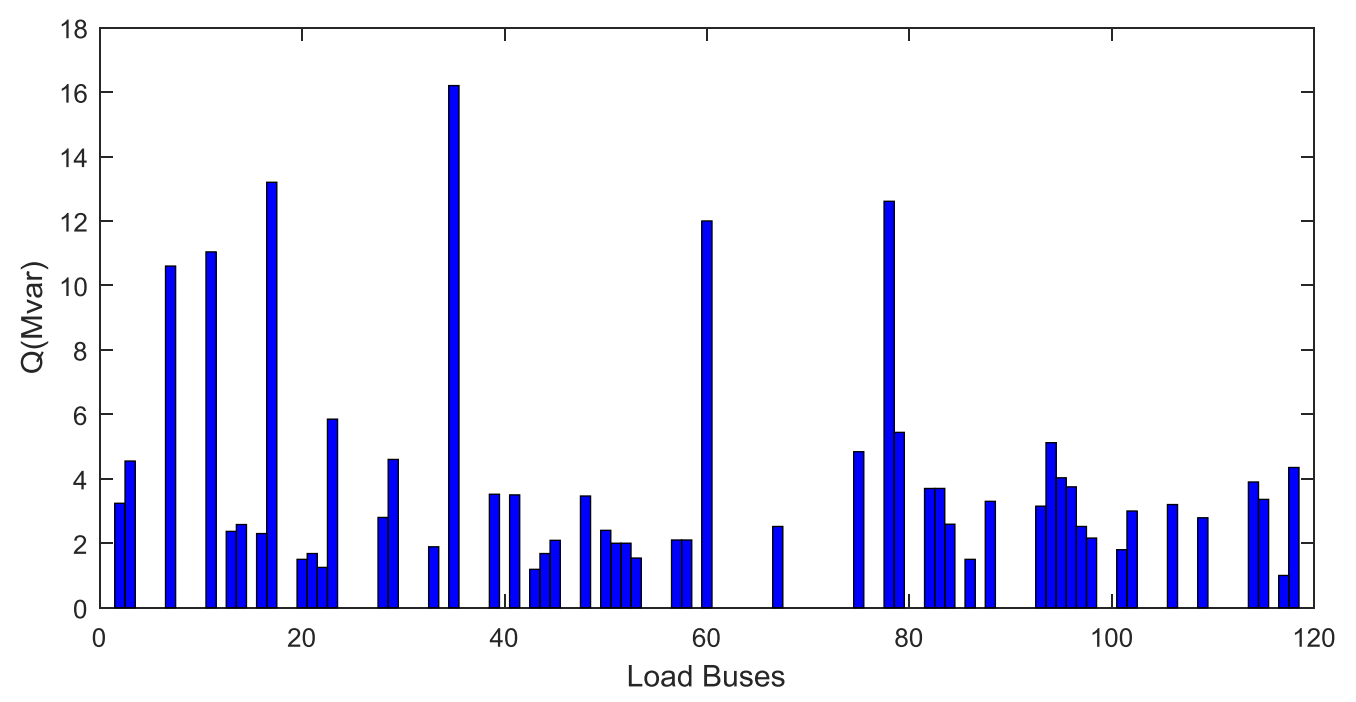

Figure 5. Maximum Permissible Reactive Loading (p.u.) of Load Buses in IEEE 118-Bus Test System

After following the algorithm of maximum loadability, we get the maximum permissible reactive loading (p.u.) of load buses in IEEE-118 system, which is given in Figure 5. On the basis these charts the voltage weak nodes and area can be identified. Following point is emerged from this analysis.

$>$ In IEEE 118 bus system, nodes 20, 22, 43, 86 and 117 are found to be voltage weak nodes of the system as these nodes have smaller permissible reactive loading and considered as the weakest area of the system. The bus 35 and 17 are most robust load buses of the area since have highest permissible reactive loading of value 16.2 p.u. and 13.2 p.u. respectively, as can see in Figure 5.

The smallest maximum loadability will be ranked the highest implying the weakest bus in the system.

\section{Conclusion}

In this process of voltage stability assessment, estimated the maximum loadability for identification of weak bus by line index indicate by FVSI and $\mathrm{L}_{\mathrm{mn}}$ used. FVSI and $\mathrm{L}_{\mathrm{mn}}$ are used to indicate the stressfulness of a line in a transmission system. In this method reactive power at a particular bus is increased until it reaches the instability point at bifurcation. At this instability point, the load connected at the particular bus is taken as the maximum loadability. This process is carried out for every bus in the system. The maximum loadability of every bus is sorted in ascending order and smallest value being ranked highest. The highest rank in the system implies the weak bus in the system, it means, it has lowest sustainable load. This technique is tested on IEEE-14 test bus system, IEEE-30 test bus system and IEEE-118 test bus system.

Following are the major highlights of this work.

(a) Two line stability indices FVSI and $\mathrm{L}_{\mathrm{mn}}$ are employed for weak bus identification. FVSI and $\mathrm{L}_{\mathrm{mn}}$ for the load buses in power system network are calculated to judge the health of the power system. Ranking of weakest buses in particular power system are decided by these indices.

(b) If the value of FVSI and $\mathrm{L}_{\mathrm{mn}}$ becomes unity, indicate that maximum connected load at that point. Among the different indices for voltage stability and voltage collapse prediction, the FVSI gives fair, accurate and consistent results. The main advantage of FVSI and $\mathrm{L}_{\mathrm{mn}}$ is the simplicity of numerical calculations and results are more expressive. 
(c) When the system is simulated with high reactive loading, the value of line index becomes lower and the system is on the verge of collapse.

(d) The proposed approach provides fast computation of voltage stability assessment. Once analyzed the system stability properly then operator can use the remedy to avoid the voltage collapse.

The proposed approach can be a beneficial tool for the assessment of voltage stability.

\section{Acknowledgements}

The authors acknowledge the support and encouragement of Malaviya National Institute of Technology, Jaipur, Swami Keshvanand Institute of Technology, Management \& Gramothan, Jaipur, Rajasthan, India.

\section{References}

[1] K R Vadivelu, "Maximum loadability estimation for weak bus identification using Fast Voltage Stability Index in a power transmission system by real time approach", IJEETC, ISSN $2319-2518$, vol. 3, no. 1, (2014)

[2] M. Fozdar, "Improvement of Voltage stability and Effects of Loadability", IEEE Universities Power Engineering Conference (UPEC-06), vol. 2, (2006), pp. 486 - 490.

[3] R. Claudia, “A Comparison of Voltage Stability Indices", IEEE MELECON 2006, May 16-19, Benalmadena (Malaga), Spain, (2006).

[4] N. Krishna, "Assessment of Voltage Stability of a Small Island Network using a Developed MATLAB Toolbox", IEEE Transmission \& Distribution Conference and Exposition-Latin America IEEE PES, (2014)

[5] Z. J. Lim, "Evaluation of the Effectiveness of Voltage Stability Indices on Different Loadings", IEEE International power engineering and optimization conference (PEOCO 2012), Melaka, Malaysia, (2012).

[6] M.V. Suganyadevi, "Estimating of Loadability Margin of a Power System by comparing Voltage Stability Indices" International conference on", control, automation, communication and energy conservation -2009, (2009).

[7] M. Ismail, "On-Line Voltage Stability Based Contingency Ranking Using Fast Voltage Stability Index (FVSI)", International conference on "IEEE/PES Transmission and Distribution Conference and Exhibition 2002, Asia Pacific, vol. 2, (2002), pp. 1118 - 1123.

[8] M. Ismail, "Novel Fast Voltage Stability Index (FVSI) for Voltage Stability Analysis in Power Transmission System", IEEE Student Conference on Research and Developing Proceeding 2002, (2002), pp. 265 - 268.

[9] T. Rajive, "Line Collapse Proximity Index for Prediction of Voltage Collapse in Power Systems", Electrical Power and Energy Systems, ELSEVIER, vol. 41, (2012), pp. 105-111.

[10] Power system Test Archive-UWEE, University of Washington. < http://www.ee.washington.edu/research/pstca>.

[11] Kumar Sharma, A. Saxena and R. Tiwari, "Voltage Stability Assessment using GVSM and Preventive Control using SVC", International Journal of Computer Applications, vol. 142, no.11, (2016).

[12] Saxena and A. Kumar Sharma, "Assessment Of Global Voltage Stability Margin Through Radial Basis Function Neural Network", Advances in Electrical Engineering, Hindawi Publishing Corporation, Article ID 4858431, 11 pages, doi:10.1155/2016/4858431, (2016).

[13] Kumar Sharma, A. Saxena and R. Tiwari, "Optimal Placement of SVC Incorporating Installation Cost", International Journal of Hybrid Information Technology, vol. 9, no.8, (2016), pp. 289-302. 